\title{
Investigating the Frequency of the ERCC1 Gene C8092A Polymorphism in Iranian Patients with Advanced Gastric Cancer
}

\author{
Sharareh Mokmeli ${ }^{1}$, Golnaz Asaadi Tehrani' ${ }^{2 *}$, Reza Eghdam Zamiri ${ }^{3}$, Tayyeb \\ Bahrami $^{4}$
}

\begin{abstract}
Background: Platinum compounds are the main drugs for treatment of advanced gastric cancer. Previous studies have shown that clinical outcome with platinum-based compounds depends on ERCC1 polymorphisms. The aim of this study was to investigate the frequency of a common polymorphism of ERCC1 gene (C8092A) in Iranian patients with advanced gastric cancer receiving platinum chemotherapy. Materials and Methods: Genetic analysis of the ERCC1 C8092A polymorphism was performed by the PCR - RFLP method using 50 paraffin-embedded tissue specimens. Results: Of the 50 cases, $32 \%$ of individuals showed CC genotype, $24 \%$ of them had CA genotype and $44 \%$ of patients had AA genotype. Conclusions: Based on the results, using of platinum-based chemotherapy would be expected to be specifically beneficial in only $32 \%$ of patients.
\end{abstract}

Keywords: Gastric cancer - ERCC1 polymorphisms - platinum-based chemotherapy

Asian Pac J Cancer Prev, 17 (3), 1369-1372

\section{Introduction}

Gastric cancer (GC) is one of the most frequent types of cancer worldwide. According to a global estimation, each year approximately 930,000 new GC cases are diagnosed (Siegel et al., 2014). There is a wide difference for incidence of GC in various ethnic and geographical areas (Malekzadeh et al., 2009). In the most common cancers ranking of Iran, GC is the first one with a probable age standardized rate (ASR) of 26.1 in men and 11.1 in women per 100,000 person-year (Alireza et al., 2005) . A number of studies have shown that GC is the second leading cause of cancer-related death worldwide. Although almost 700,000 patients die from this disease (Siegel et al., 2014), clinical choice of appropriate therapy may increase overall survival and help patients treatment.

platinum-based chemotherapy is one of the most common therapy methods for treatment GC patients (Waters et al., 1999). However, effectiveness of platinum agents in solid tumors, such as GC, is controversial (Fareed et al., 2010). Platinum trigger a set of intracellular events that eventually result in cell death, through interacts with DNA and formation predominantly intra-strand crosslink DNA adducts (Siddik, 2003; Zorbas and Keppler,
2005). These distorting lesions, in mammalian cells, are recognized and repaired by the Nucleotide Excision Repair (NER), a component of intricate network of DNA repair systems (Madhusudan and Hickson, 2005; Reardon and Sancar, 2005; Gossage and Madhusudan, 2007).

Studies have shown that ERCC1, as an excision nuclease within the NER pathway, play a crucial role in response to platinum-based chemotherapy (Bramson and Panasci, 1993; Olaussen et al., 2006; Kwon et al., 2007) and overexpression of ERCC1 is correlated with less sensitive of tumor cells to platinum therapies (Kwon et al., 2007; Fujii et al., 2008). C8092A(rs3212986) is a common polymorphism of $E R C C 1$. This polymorphism is located in 30 -untranslated region of the gene and studies have shown that it may affect the stability of ERCC1 mRNA (Chen et al., 2000). Above information suggest that C8092A polymorphism may be associated with clinical outcome in GC patients treated with platinum-based chemotherapy. In this study, using PCR-RFLP method, we determined the frequency of common polymorphisms of ERCC1 (C8092A) in 50 advanced gastric cancer patients receiving platinum chemotherapy to predict that what percentage of patients in this study these medications can be useful. 


\section{Materials and Methods}

\section{Patients and tissues}

The biopsied specimens were obtained from 50 Iranian patients with GC. The mean age of the patients was 59 years, and the study included 36 males and 14 females. These patients between 2014 and 2015 were referred to the pathology center of Valiasr hospital, Zanjan, Iran. Genotyping of ERCCl gene was performed on formalinfixed and paraffin-embedded (FFPE) sections from the tumor tissues. Written informed consent was obtained from all patients before testing. The study was approved by the ethical committee of Zanjan University of Medical sciences, Zanjan, Iran.

\section{DNA extraction}

Hematoxylin and eosin (HE)-stained slides from all GC tissues were reviewed by a pathologist. Genomic DNA was isolated from dissected tissues using the methods described by the QIAamp® DNA FFPE TissueKit (QIAGEN, Germany). Concentration and purity of DNA was quantified by spectrophotometry with NanoDrop ND-1000® -Thermo Fisher Scientific. DNA was stored at $-20^{\circ} \mathrm{C}$ before use.

\section{PCR-RFLP}

The allele and genotype frequencies of ERCC1, C8092A gene were determined by PCR-RFLP method. Polymerase chain reaction-restriction fragment length polymorphism (PCR-RFLP) on ERCC1, C8092A was performed with $250 \mathrm{ng}$ of the genomic DNA in 30- $\mu$ l reaction volume containing $1 \mu \mathrm{M}$ of each primer, 0.2 $\mathrm{mM}$ of each dNTP, $2 \mathrm{mM} \mathrm{Mgcl}{ }_{2}$, and $1 \mathrm{U}$ Taq polymerase, with $1 \times$ reaction buffer (sinaclon, Iran). Thermal cycling conditions were: initial denaturation at $95^{\circ} \mathrm{C}$ for $5 \mathrm{~min}$, followed by 35 cycles of $30 \mathrm{sec}$ at $95^{\circ} \mathrm{C}, 60 \mathrm{sec}$ at the $57.1^{\circ} \mathrm{C}$ annealing stage and $60 \mathrm{sec}$ at $72^{\circ} \mathrm{C}$. A final extension at $72^{\circ} \mathrm{C}$ for $5 \mathrm{~min}$ was carried out. The 254-bp PCR product was digested with $5 \mathrm{U}$ of MboII (fermentase Inc) at $37^{\circ} \mathrm{C}$ for $1 \mathrm{~h}$ and was resolved on a $3 \%$ agarose gel with Gel DNA Staining (Figure 1). The sizes of digested fragments were determined as follows: 254 bp products digested to 205 and $49 \mathrm{bp}$. If the product was digested, the allele was identified as A; if not, it was identified as C. Sequences of primers are shown in Table 1. These primers were designed based on the sequence of the human ERCC1 gene (GeneBank).

\section{Statistical analysis}

All statistical analysis was estimated by direct gene counting and analyzed using the chi-square test. Statistical analysis was performed with the SPSS 11.0.0 statistical software package (SPSS Inc).

\section{Results}

Table 1. Sequences of Primers Used in this Study

\begin{tabular}{ll}
\hline Polarity & \multicolumn{1}{c}{ Sequence } \\
\hline Sense & F: 5' TGAGCCAATTCAGCCACT 3' \\
Antisense & R: 5' TTTAGTTCCTCAGTTTCCCG 3' \\
\hline
\end{tabular}

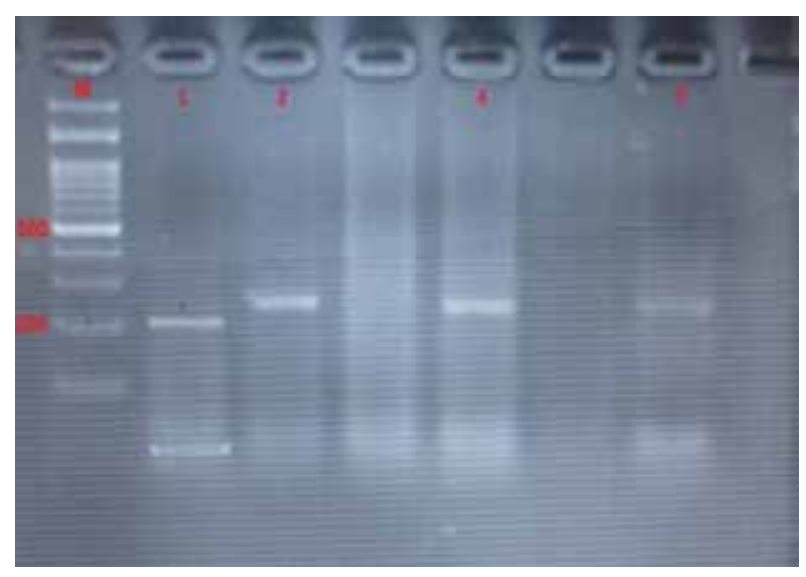

Figure 1. Electrophoresis of Digested Fragments on $3 \%$ Agarose Gel. M, is 100 bp marker, line 1 is the product of enzyme digestion process with AA genotype and bands cut to length $204 \mathrm{bp}$ and $49 \mathrm{bp}$. Lines 2, 4 and 8 are PCR products without the effect of enzyme. Line 6 is the product of digestion process with $\mathrm{CC}$ genotype and no enzymatic digestion. Size of the band is $254 \mathrm{bp}$. Line 7 is the product of Enzyme digestion process with genotype CA and bands length are 254, 204 bp and 49bp

Table 2. Allele and genotype frequencies for $\mathrm{C8092}$ polymorphism of ERCC1 gene in studied population

\begin{tabular}{lccc}
\hline ERCC1 & genotype Number (\%) & ERCC1 & Allele Frequency (\%) \\
\hline CC & $16(32 \%)$ & C & 0.44 \\
CA & $12(24 \%)$ & A & 0.56 \\
AA & $22(44 \%)$ & & \\
\hline
\end{tabular}

Histopathological analyses of our study have shown that $48 \%$ of tumor tissues were Grade II, while $42 \%$ and $10 \%$ of them were Grade III and Grade I, respectively. After PCR, digestion and electrophoresis of digested fragments (as shown in Figure 2), our results have revealed that the most frequent ( 22 cases, $44 \%$ ) of genotypes are AA, which represents wild homozygote, and CA genotype is less frequent (12 cases, $32 \%$ ) in patients, which represents heterozygote. It is also worth mentioning that frequency of non-wild homozygote (CC) was 16 of 50 cases $(32 \%)$. The allelic and genotype frequencies in patients are shown in Table 2.

\section{Discussion}

The findings of present study showed that $32 \%$ of subjects have CC genotype, $24 \%$ of them have CA genotype and $44 \%$ of them have AA genotype. The important findings in our study are that use of cisplatinbased chemotherapy will be useful only for $32 \%$ of patients and the other patients show percentage of resistance against them. It seems that this study produced results which corroborate the finding of a great deal of the previous work in this field. Over the past thirty years, numerous strides have been taken for treatment of malignant tumors. To date, the effective impact of chemotherapy, especially cisplatin-based chemotherapy is controversial. A number of seminal studies have reported 
rs3212986, rs 11615, C118T and C8092A polymorphisms affect ERCC1 mRNA expression, and subsequently clinical outcome of cisplatin chemotherapy (Stein et al., 2014). About in vitro studies, resistance to platinum associated with the expression levels of ERCC1 mRNA in ovary (Steffensen et al., 2014), testis (Schettino et al., 2008), bladder (Li et al., 2014) and lung cancers (NSCLC) (Qin et al., 2014) were studied and the existence of this relationship in patients with chronic gastric, ovarian, colon, esophagus and NSCLC cancer were confirmed (Schettino et al., 2008).

Studies have shown that high expression of ERCCl in gastric cancer patients, leading to poor survival and lack of response to cisplatin (Matsubara et al., 2008; Yamada et al., 2013). In another study Jwei et al. examined expression levels of ERCC1 and TS mRNA in advanced gastric cancer patients treated with Folfox regime using Real-time quantitative PCR. Average survival time in patients with low ERCC1 levels were considerably longer than those who have high expression levels. They concluded that an alternative chemotherapy regimen should be considered for patients with high levels of ERCC1 mRNA (Wei et al., 2008). Investigations have reported that there is a relationship between a single nucleotide polymorphism at codon $118(\mathrm{C} / \mathrm{T})$ with ERCC1 mRNA levels and clinical outcomes of cancer patients treated with platinum. Also the relationship between two common polymorphisms of ERCC1 gene (codon 118 C / T \& C8092A) and sensitivity to platinum chemotherapy in colon cancer and NSCLC patients have been reported. These polymorphisms reduce the speed of ERCCI's transcription, which led to lower levels of ERCC1 protein in nucleus (Huang et al., 2008).

In addition, Zhou et al. (2004) investigated the association between two polymorphisms of ERCC1, codon $118 \mathrm{C} / \mathrm{T}$ and $\mathrm{C} 8092 \mathrm{~A}$, which are associated with altered ERCC1 mRNA levels and mRNA stability, and overall survival (OS) in 128 advanced non-small cell lung cancer patients treated with platinum-based chemotherapy. The two polymorphisms were in linkage disequilibrium. They found that there was a statistically significant association between the $\mathrm{C} 8092 \mathrm{~A}$ polymorphism and $\mathrm{OS}(\mathrm{P}=0.006$, by log-rank test), with median survival times of $22.3(\mathrm{C} / \mathrm{C})$ and 13.4 (C/A or A/A) months, respectively, suggesting that any copies of the A allele were associated with poor outcome. No statistically significant association was found for the codon 118 polymorphism and $\mathrm{OS}(\mathrm{P}=0.41$, by log-rank test), with median survival times of 19.9 (T/T), $16.1(\mathrm{C} / \mathrm{T})$, and $13.3(\mathrm{C} / \mathrm{C})$ months, respectively. So they suggested that the ERCC1 C8092A polymorphism may be a useful predictor of OS in advanced non-small cell lung cancer patients treated with platinum-based chemotherapy (Zhou et al., 2004).

Another study which has been carried out among Chinese people with lung cancer was shown that the presence of ERCC1 118T / T and XPD 751Gln / Gln polymorphisms increase risk of death in patients with these cancers (Zhang et al., 2012). In a research was done on 2013 the impact of ERCC1 gene expression on gastric cancer cells chemical sensitivity to platinum investigated, and came to the conclusion that overexpression of $E R C C l$ is related to platinum drug resistance in gastric cancer cells (Liu et al., 2013).

In conclusion, as the previous researches provided, the existence of ERCCl gene polymorphisms causing resistance to platinum-based chemotherapy, according to results obtained in this study it can be concluded that the use of these medications will be useful only for $32 \%$ of patients surveyed in this project and the other patients show percentage of resistance and despite of spend lots of time and money they will not achieve the desired result. Accordingly, it is recommended to seek other suitable drugs for treatment such patients. Also since many patients undergoing costly and useless treatment, identification of molecular markers in tumor tissue which leads to prediction of treatment outcomes is essential for future development of chemotherapy in patients with gastric cancer. Taken together, our data support the hypothesis that C8092A polymorphism of ERCC1 gene has a significant role in clinical outcome of ciscplatin-chemotherapy and Choosing an appropriate treatment based on genetic profile of patients increase the effectiveness, reduce costs and extend the life of cancer patients.

\section{Acknowledgements}

The authors would like to announce their appreciation to all contributors who have made the achievement of this study. This work was supported by Islamic Azad University of Zanjan.

\section{References}

Alireza S, Mehdi N, Ali M, et al (2005). Cancer occurrence in Iran in 2002, an international perspective. Asian Pac J Cancer Prev, 6, 359.

Bramson J, Panasci LC (1993). Effect of ERCC-1 overexpression on sensitivity of Chinese hamster ovary cells to DNA damaging agents. Cancer Res, 53, 3237-40.

Chen P, Wiencke J, Aldape K, et al (2000). Association of an ERCC1 polymorphism with adult-onset glioma. Cancer Epidemiol Biomarkers Prev, 9, 843-7.

Fareed K, Al-Attar A, Soomro I, et al (2010). Tumour regression and $E R C C 1$ nuclear protein expression predict clinical outcome in patients with gastro-oesophageal cancer treated with neoadjuvant chemotherapy. British J Cancer, 102, 1600-7.

Fujii T, Toyooka S, Ichimura K, et al (2008). ERCC1 protein expression predicts the response of cisplatin-based neoadjuvant chemotherapy in non-small-cell lung cancer. Lung Cancer, 59, 377-84.

Gossage L, Madhusudan S (2007). Current status of excision repair cross complementing-group 1 (ERCC1) in cancer. Cancer Treatment Rev, 33, 565-77.

Huang Z-H, Hua D, Du X, et al (2008). ERCC1 polymorphism, expression and clinical outcome of oxaliplatin-based adjuvant chemotherapy in gastric cancer. World J Gastroenterol, 14, 6401.

Kwon H, Roh M, Oh S, et al (2007). Prognostic value of expression of ERCC1, thymidylate synthase, and glutathione S-transferase P1 for 5-fluorouracil/oxaliplatin chemotherapy in advanced gastric cancer. Ann Oncol, 18, 504-9.

Li S, Wu J, Chen Y, et al (2014). ERCC1 expression levels predict the outcome of platinum-based chemotherapies in advanced bladder cancer: a meta-analysis. Anti-cancer drugs, 25, 106-14. 
Liu Y-P, Ling Y, Qi Q-F, et al (2013). The effects of ERCC1 expression levels on the chemosensitivity of gastric cancer cells to platinum agents and survival in gastric cancer patients treated with oxaliplatin-based adjuvant chemotherapy. Oncol letters, 5, 935-42.

Madhusudan S, Hickson ID (2005). DNA repair inhibition: a selective tumour targeting strategy. Trends Molecular Med, 11, 503-11.

Malekzadeh R, Derakhshan MH, Malekzadeh Z (2009). Gastric cancer in Iran: epidemiology and risk factors. Arch Iran Med, 12, 576-83.

Matsubara J, Nishina T, Yamada Y, et al (2008). Impacts of excision repair cross-complementing gene 1 (ERCC1), dihydropyrimidine dehydrogenase, and epidermal growth factor receptor on the outcomes of patients with advanced gastric cancer. British J Cancer, 98, 832-9.

Olaussen KA, Dunant A, Fouret P, et al (2006). DNA repair by ERCC1 in non-small-cell lung cancer and cisplatin-based adjuvant chemotherapy. New Eng J Med, 355, 983-91.

Qin X, Yao W, Li W, et al (2014). ERCC1 and BRCA1 mRNA expressions are associated with clinical outcome of non-small cell lung cancer treated with platinum-based chemotherapy. Tumor Biology, 35, 4697-704.

Reardon JT, Sancar A (2005). Nucleotide excision repair. Progress Nucleic Acid Research Molecular Biol, 79, 183235.

Schettino C, Bareschino MA, Maione P, et al (2008). The potential role of pharmacogenomic and genomic in the adjuvant treatment of early stage non small cell lung cancer. Current genomics, 9, 252.

Siddik ZH (2003). Cisplatin: mode of cytotoxic action and molecular basis of resistance. Oncogene, 22, 7265-79.

Siegel R, Ma J, Zou Z, et al (2014). Cancer statistics, 2014. CA Cancer J Clin, 64, 9-29.

Steffensen KD, Smoter M, Waldstrøm M, et al (2014). Resistance to first line platinum paclitaxel chemotherapy in serous epithelial ovarian cancer: The prediction value of ERCC1 and Tau expression. Int J Oncol, 44, 1736-44.

Stein ME, Drumea K, Charas T, et al (2014). Platinumbased chemotherapy in primary advanced seminoma-a retrospective analysis: treatment results at the northern israel oncology center (1989-2010). rambam maimonides medical journal, 5 .

Waters J, Norman A, Cunningham D, et al (1999). Long-term survival after epirubicin, cisplatin and fluorouracil for gastric cancer: results of a randomized trial. British J Cancer, $\mathbf{8 0}$, 269.

Wei J, Zou Z, Qian X, et al (2008). ERCC1 mRNA levels and survival of advanced gastric cancer patients treated with a modified FOLFOX regimen. British J Cancer, 98, 1398-402.

Yamada Y, Boku N, Nishina T, et al (2013). Impact of excision repair cross-complementing gene 1 (ERCCl) on the outcomes of patients with advanced gastric cancer: correlative study in Japan Clinical Oncology Group Trial JCOG9912. Ann Oncol, 238.

Zhang Z-Y, Tian X, Wu R, et al (2012). Predictive role of ERCC1 and XPD genetic polymorphisms in survival of Chinese non-small cell lung cancer patients receiving chemotherapy. Asian Pac J Cancer Prev, 13, 2583-6.

Zhou W, Gurubhagavatula S, Liu G, et al (2004). Excision repair cross-complementation group 1 polymorphism predicts overall survival in advanced non-small cell lung cancer patients treated with platinum-based chemotherapy. Clin Cancer Res, 10, 4939-43.

Zorbas H, Keppler BK (2005). Cisplatin damage: are DNA repair proteins saviors or traitors to the cell? Chembiochem, 6, 1157-66. 